\title{
NEED FOR COGNITIVE CLOSURE, INFORMATION ACQUISITION AND ADOPTION OF GREEN PREVENTION AND CONTROL TECHNOLOGY
}

\begin{abstract}
In this paper, we use the OLS regression method to analyse the influencing mechanism of the NFCC on farmers' adoption of green prevention and control technology and further verify the mediating effect of information acquisition. The results show that the NFCC has a direct effect on the adoption of green prevention and control technology, and information acquisition has a mediating effect. The first stage of cognitive closure has a more significant effect on farmers' adoption of green prevention and control technology, information acquisition ability has a significant positive impact on farmers' adoption of green prevention and control technology, and information acquisition has an incomplete mediating effect on the impact of cognitive closure on the adoption of green prevention and control technologies. This paper further studies and verifies the action path of two dimensions of the NFCC on farmers' adoption of green prevention and control technology. The results have certain theoretical significance for expanding the knowledge of farmers' green prevention and control technology behaviour and further enriching the research on farmers' cognition.
\end{abstract}

Keywords: need for cognitive closure, information acquisition, rice, adoption of green prevention and control technology

\section{Introduction}

It is well known that pesticides are an important means of production in agriculture and are widely applied in agricultural production. Pesticides have improved the per unit area yields of crops such as grains, which play a vital role in securing national food security and an effective supply of important agricultural products. The no. 1 document of the central government in 2020 stated that it is necessary to tackle outstanding problems in the rural ecological environment, conduct actions to reduce pesticide and fertilizer use, strengthen the control of agricultural film pollution, and promote the comprehensive utilization of straw. In this context, developing green agriculture, promoting the effective connection between small farmers and modern agriculture and propelling the reduction of pesticide use are important measures for achieving green agricultural development. Relevant domestic and foreign studies believe that the promotion of green prevention and control technology is an effective way to reduce the use of chemical pesticides, achieve zero growth in pesticide use, and alleviate nonpoint source pollution [1, 2]. Green prevention and control technology, also known as integrated pest management (IPM), is a resource-conserving and environmentally friendly pest management technology. Its goal is to reduce the use of

\footnotetext{
${ }^{1}$ College of Economics and Management, Shenyang Agricultural University, Shenyang 110866, China, email: ayako0121@163.com

*Corresponding author: zjjm2019@syau.edu.cn
} 
chemical pesticides by farmers as much as possible while increasing crop yields. It is therefore considered to be a typical pesticide replacement technology [2, 3].

In recent years, China has established 600 demonstration bases that integrate the professional unified prevention and control of crop diseases and pests using green prevention and control and conducted green prevention and control in the entire agricultural process in $150 \mathrm{key}$ counties on a trial basis. This process exemplifies the technological model of the comprehensive treatment of crop diseases and pests and pest control with reduced pesticide use. However, green prevention and control technology is still at the popularization at present and has not become the first choice for farmers for crop disease and pesticide prevention and control behaviour. Regarding the popular effect, this technology is still mainly used for experimental demonstration and implemented at pilot locations; therefore, the actual scale of the popularization of the technology is always difficult to break through. Will farmers adopt green prevention and control technology as users? What are the key factors affecting the adoption of this technology? These questions have gradually attracted the attention of scholars.

Farmers' adoption of green prevention and control technology represents a type of technology selection behaviour in which farmers decide whether to accept and actually adopt green prevention and control technology so as to achieve the goal of maximizing their profits based on their own resource endowments and considering crop diseases and pests under the constraints of social and economic environments [1]. At present, the main mode of agriculture in China is small-scale decentralized operations. When faced with risks, farmers tend to rely on the most direct and rapid method, that is, the use of pesticides, in order to pursue economic benefits and avoid risks [4]. Even pesticide use can temporarily increase production, it may lead to poor soil and serious environmental pollution, which affect the growth and production of crops. In fact, this behaviour is very irrational. What causes this irrational choice in farmers' production behaviour? Did our previous studies ignore some assumptions? As the principal subject of agricultural production, when diseases and pests occur, farmers need to make quick judgements and choose prevention and control technology. In addition, green prevention and control technology has the characteristics of a long action cycle, slow effect and high costs, which mean that the adoption of green prevention and control technology is full of ambiguity and uncertainty for farmers. Kahneman and Tversky, who are both behavioural financial scientists, used the cognitive psychology analysis method to study human judgement and decision-making behaviour, and their study found a psychological basis for decision-making problems in fuzzy and uncertain states [5]. Cognitive psychology defines the relatively stable characteristics that people exhibit in the cognitive process as the need for cognitive closure [6]. The need for cognitive closure (NFCC) is the motivation and desire that an individual exhibits while handling a fuzzy environment. Through information processing, the NFCC ultimately influences an individual's behavioural decision [7]. In fact, farmers' final adoption of green prevention and control technology will inevitably come from their cognitive psychology. Cognitive psychology believes that the cognition of economic subjects is the basis for determining their behaviours and decisions [1].

Therefore, clarifying the intrinsic relationship between farmers' adoption of cognitive characteristics and green prevention and control technology is the key to answering the above questions. In view of this, this paper analyses the influencing mechanism of the NFCC on farmers' adoption of green prevention and control technology from the perspective of cognitive psychology, uses microsurvey data to conduct empirical tests 
and discusses how to improve the adoption of green prevention and control technology according to the cognitive characteristics of farmers' cognitive closure needs so as to effectively reduce the use of chemical pesticides, achieve negative growth of pesticide usage, and alleviate nonpoint source pollution.

\section{Literature review and research hypothesis}

Cognitive psychology believes that the perception of economic subjects is the basis for determining their behaviours and decision making [8]. In the process of agricultural production, farmers have a kind of "inertia of thinking", usually relying on past experience and even emulating others; however, they are less inclined to seek better choices after processing information, which leads to unreasonable and irrational technology selection behaviours. This "inertia of thinking" is a specific manifestation of the cognitive characteristics that farmers need for their own cognitive closure [6]. The need for cognitive closure is an individual's motivation and desire while handling a fuzzy environment, and it ultimately influences the individual's behavioural decisions through information processing [7]. In recent years, studies have found that the NFCC is a continuum and everyone is in a different position on this continuum [9]. At one end of the continuum, the NFCC is strong; while at the other end, the need to avoid closure is strong. There are also research found that when people are faced with a fuzzy state, individuals with higher cognitive closure will quickly make choices even without sufficient evidence in order to eliminate the pressure and anxiety caused by the fuzzy state as soon as possible [7]. However, individuals with lower cognitive closure have a stronger motivation to further gather information or conduct deeper analysis and consideration of information before making a choice and show a higher tolerance for ambiguity [9]. People with high cognitive closure are more likely to fall into the primary cause effect in cognition and are more inclined to adopt heuristic reasoning. Cognitive closure has a significant impact on decision-making preferences [6]. In most cases, an individual's judgement and decision-making process and decision-making preferences will be significantly affected by their information processing methods and cognitive characteristics. Under the framework of bounded rationality, the cognitive characteristics of decision makers will have an important impact on their decision-making rules. Some scholars have discovered through experimental methods that individual decision-making rules are closely related to their "needs for cognitive closure" [10]. It can be seen that the behavioural decision making of farmers is based on information processing and acquisition, so the level of the need for cognitive closure of farmers will affect their performance in decision-making processes. Those with a low need for cognitive closure rely more on normative and routine information in the information acquisition process while those with a high need for cognitive closure invest more cognitive effort in information independently and are more independent of contextual influences when making production decisions. In summary, the study of cognitive closure has become a hot topic in Western psychology for more than a decade, and it has been proven to be a variable that has an important influence on individual information processing processes, decision-making results and the individual interaction mode in a team [6]. Based on the above discussion, this paper proposes the following hypothesis:

H1: The NFCC has a significant negative influence on farmers' adoption of green prevention and control technology. 
Kruglanski [5] believe that the acquisition of cognitively closed information generally goes through two stages. The first phase is "seizing", which refers to individuals with higher cognitive closure always having a strong desire to search for information or hints with various clues in the face of uncertainty and fuzzy states so as to make more accurate judgements. In the second phase, namely, the freezing phase, individuals with higher cognitive closure will stick to their own judgements formed in the seizing phase; therefore, in the face of new information, they are more "closed" and will not adjust their positions according to new information. Their information processing is therefore rigid and inflexible.

Farmers' cognition and learning of things have their own characteristics. Farmers are more inclined to learn through practice. They often learn while doing and learn by doing, and they gradually accumulate experience. In this process, cognition and behaviour interact constantly. In agricultural production, farmers with a high NFCC tend to make excessive use of social clues, such as the recommendations of pesticide manufacturers, previous experience and the behaviour of others, in order to eliminate the ambiguity and uncertainty that may be caused by the probabilities of profits and losses. They do not process information in detail, and they show strong characteristics of heuristic thinking and reject new information that is inconsistent with the original information in order to avoid facing ambiguity and uncertainty again [11]. As a result, farmers always change their behaviour after seeing the effect, which makes their choice behaviour lag behind to some extent; and thus it is easy for farmers to make unreasonable behavioural choices.

In production, farmers are both information disseminators and recipients and users of information. Farmers' information capabilities play an important role in technology adoption behaviours and behavioural changes [12, 13]. Farmers' information capabilities can help farmers make technology adoption decisions by reducing the search costs of green prevention and control technology [14]. Information needs and information use are the key factors affecting farmers' decisions regarding pesticide use [15]. Therefore, this article hypothesizes the following:

$\mathrm{H} 2$ : Information acquisition has a significant positive impact on farmers' adoption of green prevention and control technology.

H3: The NFCC indirectly influences farmers' adoption of green prevention and control technology through information acquisition capabilities.

According to the above theoretical analysis, mapping the NFCC affects the functional channel of the adoption of green prevention and control technology. As shown in Figure 1, the NFCC has a direct negative effect on farmers' adoption of green prevention and control technology; furthermore, the NFCC can have an indirect effect on farmers' adoption of green prevention and control technology through information acquisition.

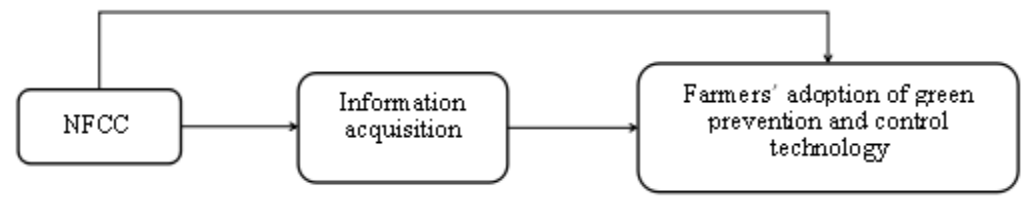

Fig. 1. Effect of NFCC on farmers' adoption behaviour of green prevention and control technology 


\section{Materials and method}

\section{Materials source}

Liaoning Province is one of the main production areas of northern Japonica rice. In 2018, rice cultivation in Liaoning Province participated in the national key special project for the "occurrence of crop diseases, pests and weeds and its key technology of green prevention and control in main producing areas of grain". Therefore, this paper selected rice growers in Liaoning Province as the object of the empirical analysis. The survey period was from October 2018 to April 2019. A total of 389 questionnaires were collected, and 345 valid questionnaires were obtained after eliminating invalid questionnaires lacking key data. The effective response rate of the questionnaires was $88.69 \%$. The survey covered 28 counties and districts in 7 cities in Liaoning Province. Among the cities, 82 valid questionnaires were collected in Panjin city, accounting for $23.77 \%$ of the total sample; 74 valid questionnaires were collected in Shenyang, accounting for $21.45 \%$ of the total sample; and 66 valid questionnaires were collected in Liaoyang city, accounting for $19.13 \%$ of the total sample. Forty-seven valid questionnaires were collected in Dandong city, accounting for $13.62 \%$ of the total samples. Thirty-two valid questionnaires were collected in Fushun, accounting for $9.28 \%$ of the total samples. Twenty-four valid questionnaires were collected in Yingkou city, accounting for $6.95 \%$ of the total samples. Twenty valid questionnaires were collected in, accounting for $5.80 \%$ of the total sample. Finally, accounting for $35.94 \%$ of the total sample.

\section{Variable selection and descriptive statistics}

Explained variable. By combining the actual popularization of green prevention and control technology in the survey area and consulting with local plant protection experts, this paper finally takes the adoption of biopesticide technology, the artificial release of natural enemies technology, insect-proof net control technology, insecticidal lamp trapping technology, colour plate trapping technology, and the adoption of insect sex lure control technology for the control of crop diseases and pest varieties as the study subjects. The adoption of plate trapping technology and insect attractant control technology was studied. We mainly inspected the selection of one or more of the green prevention and control technologies by the farmers. The measurement problem is based on a five-point Likert scale including 1 = almost all adopted, 2 = often used, 3 = occasionally used, $4=$ rarely adopted, and $5=$ not used at all. The selection of any one or more green prevention and control technologies by farmers was mainly investigated. A five-point Likert scale including $1=$ almost all adopted, $2=$ often adopted, $3=$ occasionally adopted, $4=$ rarely adopted, and $5=$ not adopted at all was used for all measurement questions.

Explanatory variables. With regard to the need for cognitive closure, this paper uses the "Cognitive Closure Needs Scale" compiled by Kruglanski [5], combined with the actual production of farmers, to design a scale for measuring farmers' NFCC (as shown in Table 1). The questions were answered using a five-point Likert scale including $1=$ very strongly disagree, 2 = less strongly disagree, $3=$ generally, $4=$ less strongly agree, $5=$ very strongly agree. In order to reduce the dimension of the variable, this paper uses principal component analysis to regress the variable. First, the correlation test is conducted for the variable indicator system required for the need for cognitive closure, and the correlation matrix is 
obtained, as shown in Table 1. The correlation matrix preliminarily shows that there is correlation between variables.

In order to further determine the correlation among variables, this paper used the SPSS 22.0 software to test the reliability and validity of the variable indicator system. we first conducts KMO (Kaiser-Meyer-Olkin) test and Bartlett's test. KMO test is used to check the correlation and partial correlation between variables, and the value is between 0 and 1 . The closer the KMO statistic is to 1, the stronger the correlation between variables and the weaker the partial correlation, the better the effect of factor analysis. In actual analysis, the effect is better when the KMO statistic is above 0.7; when the KMO statistic is below 0.5, it is not suitable to apply factor analysis at this time, and the variable structure should be redesigned or other statistical analysis methods should be considered. The results as Table 1 show that the KMO value was 0.767 , and the Bartlett's test approximate chi-squared value was 1001.393, both of which were significant $(p<0.001)$, which indicates that the factor analysis method could be used to reduce the dimensionality of variables.

Farmers' cognitive closure needs and information acquisition capacity scale

\begin{tabular}{|c|c|c|c|}
\hline Variable & Variable meaning & $\begin{array}{c}\text { Bartlett's } \\
\text { test }\end{array}$ & KMO \\
\hline \multicolumn{4}{|c|}{ NFCC } \\
\hline Nf1 & You don't like questions that can have many different answers. & \multirow{11}{*}{1001.39} & \multirow{11}{*}{0.77} \\
\hline Nf2 & $\begin{array}{l}\text { You found that your personality is suitable for a well-organized, well-behaved } \\
\text { lifestyle. }\end{array}$ & & \\
\hline Nf3 & When you go out to eat, you like to go to places you have been to before. & & \\
\hline $\mathrm{Nf4}$ & You don't like to change my plan at the last minute. & & \\
\hline Nf5 & You don't want to be with people who might make unexpected behaviours. & & \\
\hline Nf6 & You like dealing with familiar friends, because you know their habits. & & \\
\hline Nf7 & You like to behave in an orderly way. & & \\
\hline Nf8 & You like to arrange a location for everything, and never put it in a mess. & & \\
\hline Nf9 & $\begin{array}{l}\text { You feel uncomfortable when you don't know the meaning and intention of } \\
\text { someone. }\end{array}$ & & \\
\hline Nf10 & When you have a problem, you can usually find the best solution quickly. & & \\
\hline Nf11 & You am usually quick and confident when making important decisions. & & \\
\hline \multicolumn{4}{|c|}{ Information acquisition } \\
\hline $\mathrm{I} 1$ & You have extensive contacts and access to information channels. & \multirow{4}{*}{356.50} & \multirow{4}{*}{0.74} \\
\hline $\mathrm{I} 2$ & Know who to consult when you encounter a problem & & \\
\hline $\mathrm{I} 3$ & $\begin{array}{l}\text { When you encounter green control technology problems that cannot be solved, you } \\
\text { can find a solution to the channel. }\end{array}$ & & \\
\hline I4 & $\begin{array}{l}\text { I can often see information about green prevention and control technology from } \\
\text { newspapers, tv, online media and other channels. }\end{array}$ & & \\
\hline
\end{tabular}

The linear combination expression of the principal component and the need for cognitive closure index system can be obtained from the component score coefficient matrix:

$$
\begin{aligned}
& X_{1}=0.51 x_{1}+0.11 x_{2}+0.15 x_{3}+0.12 x_{4}+0.08 x_{5}+0.12 x_{6} \\
& +0.42 x_{7}+0.09 x_{8}+0.22 x_{9}+0.48 x_{10}+0.47 x_{11}
\end{aligned}
$$




$$
\begin{aligned}
& X_{2}=-0.14 x_{1}+0.5 x_{2}+0.41 x_{3}+0.47 x_{4}+0.35 x_{5} \\
& +0.36 x_{6}-0.19 x_{7}-0.18 x_{8}+0.0 x_{9}-0.13 x_{10}-0.04 x_{11}
\end{aligned}
$$

As Table 2 shows, the initial eigenvalue of the first principal component is 3.818 , and its rate of contribution to the variance is $35.345 \%$; additionally, the initial eigenvalue of the second principal component is 2.662 , and its rate of contribution to the variance is $31.973 \%$. There is a condition for extracting the principal component. The cumulative contribution of the first and second principal components accounted for $67.318 \%$ of the total variance. Principal components were extracted from common factors with eigenvalues greater than 2. According to the research on the NFCC [7], the two principal components $x_{1}, x_{2}$ are respectively named "decisiveness" and "the Need for structure". The first dimension, decisiveness, measures the characteristics of cognitive closure in the first phase, namely, the "seizing" stage. The second dimension, the need for structure, measures the characteristics of cognitive closure in the second phase, namely, the "freezing" stage [6].

Total variance explained

Table 2

\begin{tabular}{|c|c|c|c|c|c|c|}
\hline \multirow{2}{*}{ Ingredient } & \multicolumn{3}{|c|}{ Initial eigenvalue } & \multicolumn{3}{c|}{ Extract square sum loading } \\
\cline { 2 - 7 } & Total & $\begin{array}{c}\text { Contribution } \\
\text { rate of variance } \\
{[\%]}\end{array}$ & $\begin{array}{c}\text { Cumulative } \\
\text { contribution } \\
\text { rate [\%] }\end{array}$ & Total & $\begin{array}{c}\text { Contribution } \\
\text { rate of variance } \\
{[\%]}\end{array}$ & $\begin{array}{c}\text { Cumulative } \\
\text { contribution } \\
\text { rate [\%] }\end{array}$ \\
\hline 1 & 3.888 & 35.345 & 35.345 & 3.888 & 35.345 & 35.343 \\
\hline 2 & 3.517 & 31.973 & 67.318 & 3.517 & 31.973 & 67.318 \\
\hline 3 & 0.606 & 5.509 & 72.825 & & & \\
\hline 4 & 0.558 & 5.073 & 77.898 & & & \\
\hline 5 & 0.512 & 4.654 & 82.552 & & & \\
\hline 6 & 0.458 & 4.164 & 86,716 & & & \\
\hline 7 & 0.354 & 3.218 & 89.934 & & & \\
\hline 8 & 0.305 & 2.773 & 92.707 & & & \\
\hline 9 & 0.301 & 2.736 & 95.443 & & & \\
\hline 10 & 0.287 & 2.609 & 98.052 & & & \\
\hline 11 & 0.214 & 1.948 & 100.000 & & & \\
\hline
\end{tabular}

Metavariable. This paper refers to the studies of existing scholars on farmers' information capabilities [13-16], defines information acquisition as the motivation and desire of farmers to obtain available information, and designs the measurement question for the study hypothesis based on the research of this paper, as shown in Table 1. This paper continues to use the SPSS 22.0 software to extract the principal components of the variable index system, the results as shown in Table 1. The KMO value of the information acquisition ability is 0.74 , and the Bartlett spherical test approximate chi-squared value is 356.50 , both of which are significant $(p<0.001)$, indicating that the factor analysis method can be used to reduce the dimensionality of the variables. After orthogonalization rotation, a principal component was extracted, and the cumulative variance contribution rate was $51.14 \%$. The linear combination expression of the principal components and the information acquisition index system can be obtained from the component score coefficient matrix:

$$
I=0.42 i_{1}+0.51 i_{2}+0.54 i_{3}+0.53 i_{4}
$$


Control variables. The selection of the control variables in this paper is divided into two aspects, the individual characteristics of farmers and the planting characteristics of farmers, as shown in Table 3. The individual characteristic variables of the farmers include the gender and education level of the interviewed farmers. Furthermore, psychological research shows that there is a certain connection between social identity and cognitive processing: the more important one's identity is, the closer it is to the core of the self, and individuals give more cognitive resources to their information processing. The importance of social identity influences the cognitive processing of self-related social identity information. Therefore, this paper adds social identity to the variables of the individual characteristics of farmers. For farmers, planting area and planting years will affect their choice of technology. Therefore, the control variables of farmers' planting characteristics mainly include planting area and planting years. The descriptive statistics of the variables are shown in Table 3.

Table 3

Descriptive statistics of variables

\begin{tabular}{|c|c|c|c|c|c|c|}
\hline Variable & Symbol & Variable meaning & Mean & $S D$ & Max. & Min. \\
\hline \multicolumn{7}{|c|}{ Explained variable } \\
\hline $\begin{array}{c}\text { Farmers' adoption } \\
\text { behavior of green } \\
\text { prevention and control } \\
\text { technology }\end{array}$ & $\mathrm{Y}$ & $\begin{array}{c}\text { Have you adopted green } \\
\text { prevention and control } \\
\text { technology adoption in the } \\
\text { production process? }\end{array}$ & 3.4 & 1.1 & 5 & 1 \\
\hline \multicolumn{7}{|c|}{ Explanatory variables: NFCC } \\
\hline Decisiveness & $\mathrm{X}_{1}$ & $\begin{array}{l}\text { Calculated based on factor } \\
\text { score }\end{array}$ & 0.0 & 1.8 & 3.7 & -4.3 \\
\hline Need for structure & $\mathrm{X}_{2}$ & $\begin{array}{l}\text { Calculated based on factor } \\
\text { score }\end{array}$ & 0.0 & 1.5 & 4.5 & -4.2 \\
\hline \multicolumn{7}{|c|}{ Metavariable } \\
\hline $\begin{array}{c}\text { Information acquisition } \\
\text { capacity }\end{array}$ & I & $\begin{array}{l}\text { Calculated based on factor } \\
\text { score }\end{array}$ & 0.0 & 1.6 & 2.3 & -5.1 \\
\hline \multicolumn{7}{|c|}{ Control variables } \\
\hline Gender & Gender & Male $=1$, female $=0$ & 0.6 & 0.5 & 1 & 0 \\
\hline Education & Edu & $\begin{array}{c}\text { Primary school }=1 \text {, junior } \\
\text { high school }=2, \text { high school or } \\
\text { secondary school }=3 \text {, college } \\
\text { and above }=4\end{array}$ & 1.6 & 0.6 & 4 & 1 \\
\hline Farmer identity & Id & $\begin{array}{c}\text { General farmers }=1, \\
\text { professional growers }=2 \text {, large } \\
\text { professional }=3, \text { rural } \\
\text { entrepreneur }=4\end{array}$ & 1.3 & 0.6 & 5 & 1 \\
\hline Planting area & Area & $\begin{array}{c}\text { Farmers fill in according to the } \\
\text { actual situation }\left[\mathrm{m}^{2}\right]\end{array}$ & 3786.0 & 3418.7 & 20666.5 & 666.7 \\
\hline Engaged in planting time & Year & $\begin{array}{c}\text { Farmers fill in according to the } \\
\text { actual situation }\end{array}$ & 10.1 & 6.6 & 50 & 1 \\
\hline
\end{tabular}

According to the descriptive statistical results of variables, the levels of "need for structure" and "decisiveness" in the NFCC is lower than their respective median values, and farmers' adoption of green prevention and control technology is higher than the median value. Male farmers accounted for $59.09 \%$ of the farmers. The educational level of farmers was relatively low with $90.03 \%$ of the farmers below the primary and intermediate levels of education. The average planting area is 3418.68 square meters, among which only 
2 households have a planting area of more than 20000 square meters. The average planting time of farmers is 10.1 years, the shortest plating time is only one year, and the longest planting time is 50 years.

\section{Method}

The adoption of green prevention and control technology (Y), which is explained by the variables in this paper, is a continuous variable, and the measurement results are sortable. Therefore, the OLS (ordinary least square) regression or ordered probit method can be used to establish the model for empirical analysis. This paper selects the OLS regression model for empirical analysis and also uses the ordered probit model for the regression as a robustness test.

In order to test the mediating effect of information acquisition between the NFCC and the adoption of green prevention and control technology, this paper adopt the mediating effect test model [17] so as to empirically test the ways in which farmers' NFCC affects the adoption of green prevention and control technology. The basic model of intermediary inspection is:

$$
\begin{gathered}
Y=i+c X+e_{1} \\
M=i+a X+e_{2} \\
Y=i+c^{\prime} X+b M+e_{3}
\end{gathered}
$$

In equation (4), this article first checks whether the correlation between $Y$ and $X$ is significant, and if it is not significant, the analysis of the mediating effect is stopped. And $a$ is the coefficient estimate that affects the mediator variable by the explanatory variable. $c^{\prime}$ and $b$ are the coefficient estimates when the explanatory variable and the mediator variable affect the explanatory variable, respectively.

Based on the above analysis, to construct the econometric model of this paper, the need for cognitive closure of farmers requires two dimensions to influence the adoption of green prevention and control technology, as shown in equation:

$$
Y_{i}=\alpha_{i}+\beta_{i} X_{i}+\gamma_{i} C_{i}+\varepsilon_{i}
$$

$Y_{i}$ indicates the green prevention and control technology adoption behaviour of the $i^{\text {th }}$ farmer, $X_{i}$ represents the NFCC of the $i^{\text {th }}$ farmer, and $C_{i}$ represents the control variable matrix representing the $i^{\text {th }}$ farmer. Equation (7) is used to account for the cognitive closure of farmers. It is necessary to influence the total effect of green prevention and control technology adoption behaviour and to test whether the impact of cognitive closure on the adoption of green prevention and control technology is established, that is, to estimate $\beta_{i}$ and to test whether it is significant.

The measurement model after adding the information acquisition variable is as shown in equations (8) to (9):

$$
\begin{gathered}
I_{i}=a_{0}+\beta_{0} X_{i}+\gamma_{0} C_{i}+\varphi_{i} \\
Y_{i}=\alpha_{i}+\lambda_{i} I_{i}+\beta^{\prime}{ }_{i} X_{i}+\gamma_{i} C_{i}+e_{i}
\end{gathered}
$$

Equation (8) is used to measure the degree of influence of cognitive closure on the ability to acquire information on the mediator variables. Then, equation (9) is used to 
measure the indirect effect of cognitive closure on the adoption of green prevention and control technology by farmers. These modems measure $\beta_{i}, \lambda_{i}$ separately; then, $\beta_{i}, \lambda_{i}$ is the NFCC that includes the mediating effect produced by the ability to acquire information.

\section{Results and discussion}

\section{The influence of cognitive closure on farmers' adoption behaviour of green prevention and control technology}

This paper obtained the estimated results of the influence of the NFCC on farmers' adoption of green prevention and control technology, as shown in Table 4, through the gradual introduction of a series of control variables. It can be seen that the main explanatory variables are basically consistent in the symbols and saliency of the OLS and ordered probit models, indicating that the regression results are robust and the former is more effective. Therefore, the regression results of the OLS model are analysed.

Table 4

Model estimation results

\begin{tabular}{|c|c|c|c|c|c|c|c|}
\hline & \multirow{3}{*}{ Name } & \multicolumn{4}{|c|}{$\begin{array}{c}\text { Farmers' adoption behaviour of green prevention and } \\
\text { control technology }\end{array}$} & \multicolumn{2}{|c|}{ Information acquisition } \\
\hline & & \multicolumn{2}{|c|}{ OLS } & \multicolumn{2}{|c|}{ Ordered probit } & \multirow{2}{*}{\begin{tabular}{|c|} 
OLS \\
Equation (8) \\
\end{tabular}} & \multirow{2}{*}{\begin{tabular}{|c|}
$\begin{array}{c}\text { Ordered } \\
\text { probit }\end{array}$ \\
Equation (8)
\end{tabular}} \\
\hline & & Equation (7) & Equation (9) & Equation (7) & Equation (9) & & \\
\hline \multirow{4}{*}{ NFCC } & \multirow{2}{*}{ Decisiveness } & $-0.1272^{* * * *}$ & $-0.0983^{* *}$ & $-0.1287^{* * * *}$ & $-0.1021^{* *}$ & $-0.1787^{* * * *}$ & $-0.1147^{* * * *}$ \\
\hline & & $(0.0395)$ & $(0.0389)$ & $(0.0401)$ & $(0.0407)$ & $(0.0583)$ & $(0.0386)$ \\
\hline & \multirow{2}{*}{$\begin{array}{l}\text { Need for } \\
\text { structure }\end{array}$} & $-0.0885^{* *}$ & $-0.0725^{* * *}$ & $-0.0917^{* *}$ & $-0.0773^{* *}$ & $-0.0994^{*}$ & -0.0652 \\
\hline & & $(0.0409)$ & $(0.0399)$ & $(0.0417)$ & $(0.0409)$ & $(0.0605)$ & $(0.0399)$ \\
\hline \multirow{2}{*}{\multicolumn{2}{|c|}{ Information acquisition }} & & $0.1612^{* * *}$ & & $0.1751^{* * * *}$ & & \\
\hline & & & $(0.0379)$ & & $(0.0404)$ & & \\
\hline \multirow{2}{*}{\multicolumn{2}{|c|}{ Gender }} & $-0.2308^{* *}$ & $-0.2301^{* * *}$ & $-0.2327^{\text {** }}$ & $-0.2439^{* * *}$ & -0.0417 & -0.0099 \\
\hline & & $(0.1232)$ & $(0.1199)$ & $(0.1248)$ & $(0.1253)$ & $(0.1821)$ & $(0.1193)$ \\
\hline \multirow{2}{*}{\multicolumn{2}{|c|}{ Edu }} & 0.0403 & 0.0240 & 0.0343 & 0.0177 & 0.0944 & 0.0726 \\
\hline & & $(0.1026)$ & $(0.0999)$ & $(0.1035)$ & $(0.1040)$ & $(0.1511)$ & $(0.0996)$ \\
\hline \multirow{2}{*}{\multicolumn{2}{|c|}{ Id }} & $0.1896^{* *}$ & $0.1417^{* *}$ & $0.3441^{* *}$ & $0.2276^{* *}$ & $0.1631^{* *}$ & $0.1973^{* *}$ \\
\hline & & $(0.0823)$ & $(0.0680)$ & $(0.1449)$ & $(0.1064)$ & $(0.0702)$ & $(0.0904)$ \\
\hline \multirow{2}{*}{\multicolumn{2}{|c|}{ Area }} & $0.0271^{* *}$ & $0.0679^{* * *}$ & $0.0445^{* *}$ & $0.0372^{* *}$ & -0.0002 & -0.0098 \\
\hline & & $(0.0118)$ & $(0.0283)$ & $(0.0213)$ & $(0.0157)$ & $(0.0180)$ & $(0.0119)$ \\
\hline \multirow{2}{*}{\multicolumn{2}{|c|}{ Year }} & 0.0061 & 0.0071 & -0.0061 & -0.0076 & -0.0064 & 0.0124 \\
\hline & & $(0.0099)$ & $(0.0096)$ & $(0.0099)$ & $(0.0099)$ & $(0.0145)$ & $(0.0095)$ \\
\hline & cons & 3.8106 & 3.7616 & & & 0.3036 & \\
\hline & /cut1 & & & -2.1702 & -2.1735 & & -2.8589 \\
\hline & /cut2 & & & -1.3411 & -1.3459 & & -1.8854 \\
\hline & /cut3 & & & -0.3165 & -0.2893 & & -0.8949 \\
\hline & /cut4 & & & 0.5904 & 0.6640 & & 0.3856 \\
\hline & $\mathrm{F}$ & $27.64^{* * * *}$ & $46.29^{* * *}$ & & & $35.61^{* *}$ & \\
\hline & Chi2 & & & $24.39^{* * * *}$ & $43.55^{* * *}$ & & $14.21^{* *}$ \\
\hline & seudo R2 & 0.0775 & 0.1298 & 0.0270 & 0.0482 & 0.0473 & 0.0057 \\
\hline
\end{tabular}

${ }^{*}$ indicates a significant level of $10 \%,{ }^{* *}$ indicates a significant level of $5 \%$, and ${ }^{* * *}$ indicates a significant level of $1 \%$ 
The estimation results of equation (7) in Table 4 show that the need for cognitive closure has a significant negative impact on farmers' adoption of green prevention and control technology, that is, farmers with high cognitive closure have a low degree of adoption of green prevention and control technology. Specifically, decisiveness and the need for structure have significant negative effects on the adoption of green prevention and control technology. That is, in the "seizing" phase of cognitive closure, when farmers are faced with the uncertainty and ambiguity of new technologies, farmers with high cognitive closure tend to search for all kinds of clues with hints, especially social clues, in order to quickly make judgements on target things in order to eliminate ambiguity. In the "freezing" stage of cognitive closure, farmers with high cognitive closure will stick to their judgements made in the first stage and are not likely to make changes. Therefore, farmers with high cognitive closure will make behavioural decisions based on previous planting experience without thinking in order to eliminate uncertainty immediately. After gradually adding control variables, it was found that gender, peasant household identity and planting area significantly affect farmers' adoption of green prevention and control technology. In other words, male farmers adopt green prevention and control technology to a higher degree. The more important the role of the farmer's identity in the village is, the more it contributes to the adoption of green prevention and control technology. The higher the planting area is, the higher the degree of adoption of green prevention and control technology.

\section{The influence of information acquisition on farmers' adoption of green control and prevention technology}

In this part, a single equation regression strategy is adopted to empirically test the influence of information acquisition on information acquisition capabilities while introducing the same control variables. The estimated results are shown in equations (8) and (9) in Table 4. Since the information acquisition ability is a continuous variable, this part of the regression uses the OLS regression method. According to the regression results, the NFCC has a significant negative impact on information acquisition; that is, the higher the cognitive closure of the farmer is, the lower the desire for information acquisition. Specifically, decisiveness negatively affects information acquisition at the $1 \%$ level, and the need for structure negatively affects information acquisition at the $10 \%$ level. The estimation results show that the "seizing" in the first phase of cognitive closure has a very significant effect on farmers' information acquisition behaviour while the "freezing" in the second phase of cognitive closure has an insignificant effect on information acquisition ability. The regression results give a more interesting theoretical conjecture: the results may occur because as the farmers enter the second phase of cognitive closure, in order to consolidate the judgements they made in the first phase, when facing new information, they become more "closed" and more inclined to use existing experience or follow others' choices and will not easily accept new information, which verifies the theoretical assumptions of this paper. Moreover, farmers' identity, as the control variable, has a significant positive effect on their information acquisition. It can be concluded that farmers with high cognitive closure have a lower desire for information acquisition. The more important the role that farmers play in the village, the stronger their desire is for information acquisition. 
Furthermore, it can be seen from the regression results of equation (8) that information acquisition has a significant positive impact on farmers' adoption of green prevention and control technology, and the identity of farmers in the control variables significantly positively affects farmers' adoption of green prevention and control technology. That is, cognitive closure significantly affects farmers' adoption of green prevention and control technology through information acquisition. Next, this paper will further test the mediating effect of information acquisition.

\section{Mediating effect of information acquisition}

This paper applies the stepwise test regression coefficient method [17] to test the mediating effect of information acquisition capability. The specific steps are as follows. First, check the coefficient of equation (4) (i.e., check H0: $\beta_{n i}=0$ ). Then, test the coefficients of equation (8) (i.e., test $\mathrm{HO}: \beta_{0}=0$ ) and the coefficients of equation (9) (i.e., test $\mathrm{H} 0: \beta^{\prime}{ }_{n i}=0$ ). If the coefficient $\beta_{n i}$ is significant and both coefficients $\beta_{0}$ and $\beta_{n i}{ }_{n i}$ are significant, the mediating effect is significant. If $\lambda_{n i}$ is not significant, the effect is a complete mediating effect

Table 5

Intermediary effect test results

\begin{tabular}{|c|c|c|}
\hline Mediating effect test & Decisiveness & Need for structure \\
\hline$a$ & $-0.1787^{* * *}$ & $-0.0994^{*}$ \\
\hline$b$ & $0.1612^{* * *}$ & $0.1612^{* * *}$ \\
\hline Mediating effect $(a \times b)$ & -0.0288 & -0.0161 \\
\hline Direct effects $\left(c^{\prime}\right)$ & $-0.0983^{* * *}$ & $-0.0725^{* * *}$ \\
\hline Mediating effect/direct effects [\%] & 29.30 & 22.07 \\
\hline Test results & Founded intermediary & Founded intermediary \\
\hline
\end{tabular}

${ }^{*}$ indicates a significant level of $10 \%,{ }^{* *}$ indicates a significant level of $5 \%$, and ${ }^{* * *}$ indicates a significant level of $1 \%$.

According to the results of the mediation effect test in Table 5, the need for cognitive closure has significant direct and indirect effects on the pesticide application behaviour of farmers. First, the coefficient of the direct effect of decisiveness on information acquisition is $a=-0.1787$, the coefficient of the direct effect of information acquisition on the adoption green prevention and control technology is $b=0.1612$, and the coefficient of the direct effect of decisiveness on the adoption of green prevention and control technology is $c^{\prime}=-0.0983$. The coefficient of the indirect effect of decisiveness for the adoption of prevention and control of green technology is $0.0288(0.1787 \times 0.1612)$, suggesting that when other conditions remain unchanged, the adoption of green prevention and control technology will decrease by 0.0288 units for every 1 unit increase in farmers' decisiveness, but it is smaller than the absolute value of the direct effect of decisiveness on the adoption of green prevention and control technology by 0.1716 . The estimated path coefficients $a, b$, and $c^{\prime}$ of the model are all significant, indicating that the mediating effect of decisiveness through the mediating variable of information acquisition on the adoption of green prevention and control technology is significant and is not completely intermediary.

In addition, the coefficient of the direct effect of the need for structure on information acquisition is $a=-0.0994$, the coefficient of the direct effect of information acquisition on the adoption of green prevention and control technology is $b=0.1612$, and the coefficient 
of the direct effect coefficient of the need for structure on pesticide application behaviour is $c^{\prime}=-0.0725$. The indirect effect coefficient of the need for the structure on pesticide application behaviour is $-0.016(-0.0994 \times 0.1612)$, which means when the other conditions remain unchanged, the degree of adoption of green prevention and control technology will decrease by -0.016 units for every 1 unit increase in the need for structure; however, the direct effect of the need for the structure on the adoption of green prevention and control technology is less than 0.0725 . The estimated path coefficients $a, b$, and $c^{\prime}$ of the model are all significant, indicating that the mediating effect of the structural demand on the adoption of green prevention and control technology through the mediating variable of information acquisition is significant and is not completely intermediary.

\section{Conclusion}

This paper uses empirical data to test the influencing mechanism of the NFCC on the adoption of green prevention and control technology. The OLS regression method is adopted to fully control the individual characteristics, planting characteristics and information acquisition capabilities of farmers to analyse and test their adoption of green prevention and control technology. On this basis, the mediating effect test method is further applied to empirically test the intermediary channels of cognitive closure affecting farmers' adoption of green prevention and control technology. This paper finds that the NFCC has a direct effect on the adoption of green prevention and control technology, and information acquisition has a mediating effect. Specifically, both decisiveness and need for structure have incomplete mediating effects on the adoption of green prevention and control technology through information acquisition. The possible reason is that farmers with high cognitive closure are more inclined to use social clues, and even their own limited rationality is not used; however, they directly emulate others, showing strong characteristics of heuristic thinking and rejecting new information that is inconsistent with the original information, thus affecting their adoption of green prevention and control technology. Furthermore, the above conclusions first validate the general study conclusions in academic circles, that is, cognition significantly affects the technology adoption behaviour of farmers. This paper further studies and verifies the action path of two dimensions of the NFCC on farmers' adoption of green prevention and control technology. The results have certain theoretical significance for expanding the study of farmers' green prevention and control technology behaviour and further enriching the research on farmers' cognition.

\section{Policy suggestion}

Under the background of striving to develop green agriculture and promoting the effective connection between small farmers and modern agriculture, the findings of this paper have important theoretical and realistic significance for promoting the popularization of green prevention and control technology behaviour, achieving negative growth of pesticide usage and alleviating nonpoint source pollution. To this end, this paper proposes the following policy recommendations: first, the cognitive characteristics of farmers should be fully used and a popularizing strategy that promotes work in all areas by drawing upon the experience gained in key pilot places should be formulated. The enthusiasm of village cadres and village talent to participate in green prevention and control technology should be fully mobilized; and the characteristics of farmers' cognitive closure, especially the 
cognitive characteristics and information acquisition characteristics of "seizing" in the first phase, should be used so as to achieve a leading effect. The second recommendation is to gradually weaken the fuzziness and uncertainty of farmers' adoption of green prevention and control technology. Publicity activities on green prevention and control technologies should be actively conducted to improve farmers' understanding of green prevention and control technology behaviours. Furthermore, the government can appropriately adopt subsidy policies to help farmers who adopt green prevention and control technologies and assign professionals to provide guidance on green prevention and control technologies and provide technical assistance. The third recommendation is to enhance the ability of farmers to obtain information. It is necessary to continuously improve the construction of information services, establish a sound agricultural technology extension system, and enrich the information access channels of farmers.

There are certainly still some limitations in this study. First, the conclusions of this paper are based on farmers in Liaoning Province, but whether consistent conclusions can be reached in other parts of China remains to be verified. Second, green prevention and control technology is a complex technology package that includes multiple subtechnologies. This paper only examines the extent to which farmers adopt green prevention and control technology. In further studies, specific content or specific technologies can be included in the analysis framework to more deeply explore the role of the NFCC and information acquisition capabilities.

\section{Acknowledgements}

This work was supported by NSFC71473167 (Information Acquisition, Anchor Adjustment and Vegetable Farmers' Behaviour of Pesticides Application: Mechanism and Evidence); L18BGL012 (Research on Social Trust, Risk Perception and Farmers' Pesticide Application Behaviour).

\section{References}

[1] Pan Y, Ren Y, Luning PA. Factors influencing Chinese farmers' proper pesticide application in agricultural products - A review. Food Control. 2021;122:107788. DOI: 10.1016/j.foodcont.2020.107788.

[2] Gao Y, Zhao D, Yu L. Duration analysis on the adoption behavior of green control techniques. Environ Science Pollut Res. 2019;26:6319-27. DOI: 10.1007/s11356-018-04088-9.

[3] Arthanareeswaran G, Curcio S, Chakraborty S. Special Issue: Green technologies for environmental pollution control and prevention. Ecotoxicol Environ Safety. 2015;134(pt.2):287. DOI: 10.1016/j.ecoenv.2016.09.032.

[4] Pan D, He M, Kong F. Risk attitude, risk perception, and farmers' pesticide application behavior in China: A moderation and mediation model. J Cleaner Prod. 2020;276(10):124241. DOI: 10.1016/j.jclepro.2020.124241.

[5] Kruglanski AW, Webster DM, Klem A. Motivated resistance and openness to persuasion in the presence or absence of prior information. J Pers Soc Psychol. 1993;65(5):861-76. DOI: 10.1037/0022-3514.65.5.861.

[6] De Dreu CKW, Koole SL, Oldersma FL. On the seizing and freezing of negotiator inferences: Need for cognitive closure moderates the use of heuristics in negotiation. Addiction. 1999;25(3):348-62. DOI: $10.1177 / 0146167299025003007$.

[7] Keersmaecker JD, Dunning D, Pennycook G, Rand DG, Roets A. Investigating the robustness of the illusory truth effect across individual differences in cognitive ability, need for cognitive closure, and cognitive style. Personality Social Psychol Bull. 2020;46(2):204-15. DOI: 10.1177/0146167219853844.

[8] Simon HA. Theories of bounded rationality. Decision Organization. 1972:161-76. Available from: https://mathscinet.ams.org/mathscinet-getitem?mr=418864.

[9] Webster DM, Kruglanski AW. Individual differences in need for cognitive closure. J Personality Social Psychol. 1994;67(6):1049-62. DOI: 10.1037/0022-3514.67.6.1049. 
[10] Andrews D. The interplay of information diagnosticity and need for cognitive closure in determining choice confidence. Psychol Marketing. 2013;30(9):749-64. DOI: 10.1002/mar.20643.

[11] Neuberg SL, Judice TN, West SG. What the need for closure scale measures and what it does not: Toward differentiating among related epistemic motives. J Personality Social Psychol. 1997;72(6):1396-412. DOI: 10.1037/0022-3514.72.6.1396.

[12] Song Y, Fan T, Tang Y. Quality information acquisition and ordering decisions with risk aversion. Int J Prod Res. 2020;(6):1-17. DOI: 10.1080/00207543.2020.1828640.

[13] Guo ML, Jia XP, Huang JK, Kumar KB, Burger NE. Farmer field school and farmer knowledge acquisition in rice production: Experimental evaluation in China. Agricult Ecosystems Environ. 2015;209:100-7. DOI: 10.1016/j.agee.2015.02.011.

[14] Thuo M, Bell AA, Bravo-Ureta BE, Lachaud MA, Puppala N. Effects of social network factors on information acquisition and adoption of improved groundnut varieties: the case of Uganda and Kenya. Agricult Human Values. 2014;31(3). DOI: 10.1007/s10460-014-9486-6.

[15] Genius, M, Pantzios, CJ, Tzouvelekas V. Information acquisition and adoption of organic farming practices. J Agricult Resource Economics. 2006;31. DOI: 10.1080/028418500127345064.

[16] Colombo L, Femminis G, Pavan A. Information acquisition and welfare. Discussion Papers. 2014;81(4):1438-83. DOI: 10.1093/restud/rdu015.

[17] Preacher KJ, Hayes AF. SPSS and SAS procedures for estimating indirect effects in simple mediation models. Behavior Res Methods Instruments Computers. 2004;36(4):717-31. DOI: 10.3758/BF03206553. 